\title{
Biocompatibility and biodegradation of polyester and polyfumarate based-scaffolds for bone tissue engineering
}

\author{
M. Susana Cortizo ${ }^{1}$, M. Silvina Molinuevo ${ }^{2}$ and Ana M. Cortizo ${ }^{2 *}$ \\ ${ }^{1}$ Instituto de Investigaciones Fisicoquímica Teóricas y Aplicadas (INIFTA), Facultad de Ciencias Exactas, Universidad Nacional de La \\ Plata, 1900 La Plata, Argentina \\ ${ }^{2}$ Catedra de Bioquímica Patológica, Facultad de Ciencias Exactas, Universidad Nacional de La Plata, 1900 La Plata, Argentina
}

\begin{abstract}
Biodegradable and biocompatible polymeric scaffolds have been recently introduced for tissue regeneration purpose. In the present study we aimed to develop polymeric-based scaffolds for bone regeneration. Two polyesters, poly- $\beta$-propiolactone (PBPL), poly- $\varepsilon$-caprolactone (PCPL) and two polyfumarates, polydiisopropyl fumarate (PDIPF), polydicyclohexyl fumarate (PDCF) were chosen to prepare films which can support osteoblastic growth. Scanning electron microscopy and water contact angle were used to characterize the matrices. Biodegradation studies were performed both in PBS buffer and using an in vitro macrophage degradation assay. Mouse calvaria-derived MC3T3E1 cells and UMR106 rat osteosarcoma cell lines were used to perform biocompatibility and cytotoxicity studies. The polyesters, the most hydrophilic polymers studied, showed a rougher and more porous surfaces than the polyfumarates. Under acellular conditions, only PBPL was degraded by hydrolytic mechanisms. However, macrophages performed an active degradation of all polymeric films. Osteoblasts developed well-defined actin fibres without evidence of cytotoxicity when growing on the films. The number of UMR106 osteoblasts that adhered to the PBPL-based film was higher than that of the cells attached to the PECL and polyfumarates (PDIPF and PDCF) matrices. Both UMR106 and MC3T3E1 osteoblastic lines showed protein levels comparable to control conditions, demonstrating that they grew well on all surfaces. However, UMR106 cells showed a significant increase in proliferation on polyester-derived scaffolds (PBPL and PECL). The alkaline phosphatase activity of UMR106, an osteoblastic marker, was significantly higher than that of control plastic dishes. MC3T3E1 cells expressed similar levels of this differentiation marker in all polymeric matrices. We found similar collagen protein content after $48 \mathrm{~h}$ culture of UMR106 cells on all surfaces. However, important differences were evident in the MC3T3E1 line. In conclusion, the synthetic polymeric-based scaffold we have developed and studied supports adhesion, growth and differentiation of two osteoblastic cell lines, suggesting that they could be useful in bone tissue regeneration. Copyright $\odot 2008$ John Wiley \& Sons, Ltd.
\end{abstract}

Received 13 August 2007; Accepted 24 December 2007

Keywords bone tissue engineering; biocompatibility; polyesters; polydialkyl fumarates; biodegradation; film morphology

\section{Introduction}

*Correspondence to: Ana M. Cortizo, Catedra de Bioquímica Patologica, Facultad de Ciencias Exactas, Universidad Nacional de La Plata, 47 y 115, 1900 La Plata, Argentina.

E-mail: cortizo@biol.unlp.edu.ar
Bone tissue engineering techniques have become an expanding research area in regenerative medicine (Liu and Ma, 2004; Lutolf and Hubbell, 2005; Mano et al., 2007). These strategies are based on the use of artificial 
extracellular matrix or scaffolds to restore the structure and function of damaged or dysfunctional tissues. The concomitant use of osteoblasts and regulatory growth factors has improved and extended the therapeutic applications of synthetic polymeric devices (Buma et al., 2004; Salgado et al., 2004; Fini et al., 2004). The first approach in the selection of a suitable scaffold should be the evaluation of in vitro cytotoxicity, using cells in culture, as well as its biocompatibility. The osteointegration of biomaterials depends in part on the scaffold properties, such as wettability, surface charge, topography and appropriate porosity (Freyman et al., 2001; Habibovic and de Groot, 2007). In addition, adequate bone tissue biocompatibility could be expected from materials whose physicochemical properties promote cell adhesion, proliferation and differentiation into mature osteoblasts (Behravesh et al., 2003; Fini et al., 2004). Furthermore, an ability to be gradually degraded into non-toxic products, by hydrolysis or enzymatic degradation, is also important, as the scaffold serves as only a temporary support of bone (Hedberg et al., 2005).

Several kinds of materials have been used for construction of scaffold devices for bone tissue engineering (Hench and Polak, 2002). Both biologically derived and synthetic materials have been extensively explored in regenerative medicine (Lutolf and Hubbell, 2005). In particular, synthetic polymeric materials, such as poly(lactic acid), poly(glycolic acid) and poly(lactide-co-glycolide), have received considerable attention, since their properties of biocompatibility and biodegradation make them attractive for therapeutic applications (Lee et al., 2006; Mano et al., 2004; Peter et al., 1998, Sarasam and Madihally, 2005). However, these materials exhibit insufficient mechanical strength to support bone regeneration. Other authors have extensively explored the use of the aliphatic cross-linked polyester poly(propylene fumarate) as a degradable scaffold for bone tissue engineering (He et al., 2001; Timmer et al., 2003). Homopolyalkyl fumarates have a skeleton composed of a linear structure of $\mathrm{C}-\mathrm{C}$, which reduces its biodegradability in comparison with polyesters. However, polyfumarates would be expected to exhibit better mechanical properties than polyesters. Our group has previously described a rapid and efficient method to synthesize polydialkyl fumarates of high molecular weight, based on a new methodology that uses microwave energy (Cortizo et al., 2007). We were interested in selecting new materials (polyesters and polyfumarates) and to compare their ability to act as a scaffold for bone tissue. Polyesters (poly- $\beta$-propiolactone and poly- $\varepsilon$-caprolactone) were selected due to their different degradation behaviour, based on structural characteristics such as the number of methylene groups along the main chain.

In this study we aimed to develop two kinds of scaffold for bone regeneration, based on polyfumarate and polyester polymers. We evaluated their cytotoxicity, biocompatibility and degradability using bone-related cell lines in culture.

\section{Materials and methods}

\subsection{Synthesis and characterization of polymers}

Poly- $\beta$-propiolactone (PBPL) used in this work was previously synthesized in our laboratory through anionic polymerization and was further characterized (Rosenvasser et al., 1982). Briefly, the polymerization was carried out in a reaction tube attached to a high vacuum line, using methylene dichloride as the solvent. The initiator was potassium acetate, with dibenzo-18-crown- 6 ether $(1: 1$ molar) as complexing agent. A $3.3 \mathrm{M}$ monomer concentration and 1000 ratio of monomer to initiator were used. The reaction was conducted at $35^{\circ} \mathrm{C}$ for $2 \mathrm{~h}$ and finally the polymer was precipitated with ethyl ether and dried in vacuum at room temperature.

Poly- $\varepsilon$-caprolactone (PECL) was synthesized in our laboratory by adaptation of the methodology of $\mathrm{Yu}$ et al. (2004). The ring-opening polymerization of $\varepsilon$ caprolactone initiated by benzoic acid (15:1 molar ratio) was carried out under microwave irradiation (350 W irradiation for $30 \mathrm{~min}$ ). A domestic oven (Zenith, ZVP-2819) was used. After reaction, the polymer was isolated by methanol addition, purified by dissolution-precipitation (chloroform:methanol, 1:5) and dried until constant weight was achieved.

Poly(diisopropylfumarate) (PDIPF) and poly(dicyclohexylfumarte) (PDCF) were synthesized by microwaveassisted radical polymerization, using benzoyl peroxide as the initiator (Cortizo et al., 2007). Briefly, $1 \mathrm{~g}$ monomer was added to a previously weighed amount of initiator (60 mM) under nitrogen gas into a $25 \mathrm{~cm}^{3}$ conical Pyrex flask closed by a septum. The reactor was irradiated for $2 \mathrm{~min}$ at $140 \mathrm{~W}$ or for $30 \mathrm{~min}$ at $70 \mathrm{~W}$ for DIPF or DCF, respectively. After reaction, the polymers were isolated and purified by solubilization-precipitation (toluene: methanol, 1:8) and dried until constant weight was achieved.

The weight average molecular weight $\left(\mathrm{M}_{\mathrm{w}}\right)$ and molecular weight distribution were determined by size exclusion chromatography (SEC) in a LKB-2249 instrument at $25^{\circ} \mathrm{C}$. A series of $\mu$-Styragel columns in the pore size range $10^{5}, 10^{4}, 500$ and $100 \AA$ were used, with chloroform as an eluent. The polymer concentration was $4-5 \mathrm{mg} / \mathrm{ml}$ and the flow rate was $0.5 \mathrm{ml} / \mathrm{min}$. The polymer was detected at $5.75 \mu \mathrm{m}$ using a Miran 1A spectrophotometer detector, and calibration was done by the standard procedure, using a polymethyl methacrylate standard. Table 1 shows the relevant properties of the polymer samples used in this study.

Table 1. Physicochemical properties of the polymers

\begin{tabular}{lcc}
\hline Polymer & $\begin{array}{c}\text { Average molecular } \\
\text { weight, } \mathrm{M}_{\mathrm{w}}(\mathrm{g} / \mathrm{M})\end{array}$ & $\begin{array}{c}\text { Polydispersity } \\
\text { index } \mathrm{M}_{\mathrm{w}} / \mathrm{M}_{\mathrm{n}}\end{array}$ \\
\hline PBPL & 45100 & 1.4 \\
PEPL & 24900 & 1.3 \\
PDIPF & 74000 & 1.5 \\
PDCF & 84700 & 3.6 \\
\hline
\end{tabular}




\subsection{Preparation and characterization of the cast films}

Polymer films were prepared by solvent casting. A solution of the polymer in chloroform $(5 \% \mathrm{w} / \mathrm{w})$ was prepared and was poured onto glass Petri dishes $\left(19.6 \mathrm{~cm}^{2}\right)$. The solvent was allowed to evaporate at room temperature, and then the resulting films were dried under vacuum until constant weight, sterilized in an autoclave at $121^{\circ} \mathrm{C}$ for $20 \mathrm{~min}$ and finally stored in desiccators until use.

Water droplet contact angle measurements were performed on the surface of polymer films, using deionized water at room temperature. Water was dropped onto the films and photographed using a Nikon camera supplied with a EF $50 \mathrm{~mm} \mathrm{f/25}$ macro lens. The contact angle was then analysed using a computer.

\subsection{Scanning electron microscope}

The surfaces of the matrices were coated with gold and their morphology was examined using scanning electron microscopy (SEM; Phillips 505, The Netherlands), with a accelerating voltage of $20 \mathrm{kV}$, and the images were analysed using Soft Imaging System ADDAII.

\subsection{In vitro degradation}

The degradation assay was carried out by immersing the polymer film in phosphate buffer solution at $37^{\circ} \mathrm{C}$, as previously described in detail (Cortizo et al., 2001). At appropriate times (every $15 \mathrm{~min}$ during the initial $2 \mathrm{~h}$, then every hour until $5 \mathrm{~h}$, and finally every day for 7 days), the supernatants were removed and replaced by $5 \mathrm{ml}$ fresh buffer. At the end of the experiments, samples of the films were recovered to evaluate possible changes in the molecular weight distribution of the polymers.

Considering that eventually some of the films would not be degraded under these conditions, assays of in vitro degradation by macrophages were also performed (Mabilleau et al., 2004). For this purpose, RAW264.7 macrophages were sub-cultured over different films and cultured in 10\% Fetal bovine serum - Dulbeccos Modified Eagle's medium (FBS-DMEM). After 21 days of culture, the cells were eliminated from the films with $0.1 \%$ Triton$\mathrm{X} 100$. The films were then exhaustively washed with PBS, water and finally with methanol and dried until constant weight. The insoluble fraction was solubilized with chloroform and the average molecular weight and polydispersity index were determined by SEC (Gough et al., 2004). Alternatively, a film of polydiisopropyl fumarate with the fluorescent end-group 3-phenylazobenzoyle was synthesized (Cortizo et al., 1989). This polymer, designated PDIF*, has an average molecular weight and polydispersity index of 83000 and 2.1, respectively, as determined by SEC. RAW264.7 cells were cultured on this film and after 21 days, macrophages were observed with a Nikon fluorescence microscope and images were captured with a digital camera.

\subsection{Cell cultures and incubations}

UMR106 rat osteosarcoma cells and MC3T3E1 mouse calvaria-derived cells were grown in DMEM containing $10 \% \mathrm{FBS}, 100 \mathrm{U} / \mathrm{ml}$ penicillin and $100 \mu \mathrm{g} / \mathrm{ml}$ streptomycin at $37^{\circ} \mathrm{C}$ in a $5 \% \mathrm{CO}_{2}$ atmosphere (McCarthy et al., 1997). Cells were seeded on $75 \mathrm{~cm}^{2}$ flasks, sub-cultured using trypsin-EDTA. The UMR106 cell line has been shown to conserve certain characteristics of differentiated osteoblastic phenotype (Partridge et al., 1983). In the case of non-transformed MC3T3E1 cells, previous studies have demonstrated that expression of osteoblastic markers begins after culturing the cells with medium supplemented by $5 \mathrm{~mm} \beta$-glycerol-phosphate ( $\beta \mathrm{GP}$ ) and $25 \mu \mathrm{g} / \mathrm{ml}$ ascorbic acid (AA) (Quarles et al., 1992). Under these culture conditions, alkaline phosphatase (ALP) activity begins to be expressed after 1 week and reaches a maximum after 2 weeks, while mineralization is achieved after extending the culture to 3 weeks. However, the cells only undergo active replication during the first 5 days of incubation. For adhesion and proliferation experiments with both cell lines and differentiation experiments with UMR106 osteoblasts, cells were seeded on polymeric matrix-coated dishes and were incubated in 10\% FBS medium during the periods of time indicated in the legend of figures. For ALP expression and collagen production experiments with MC3T3E1 osteoblasts, the cells were cultured for 2 weeks in FBS-DMEM supplemented with $\beta$-glycerol-phosphate and ascorbic acid, changing the medium every 2 days.

\subsection{Cell adhesion}

The adhesion assay was performed as previously reported (McCarthy et al., 2004). Briefly, cells were plated in DMEM-10\% FBS at a seeding density of $10^{5}$ cells $/ \mathrm{ml}$ and allowed to adhere for $1 \mathrm{~h}$ at $37^{\circ} \mathrm{C}$. Each dish was then washed with phosphate-buffered saline (PBS), fixed with methanol for $10 \mathrm{~min}$ and stained with Giemsa. The number of adhered cells was evaluated by microscopy, counting several representative fields per well.

\subsection{Cell morphology}

Inmunofluorescence assay of actin fibres was used to analyse possible changes in cell morphology, as well as in osteoblast integration/interactions with biomaterials. Osteoblasts were cultured in DMEM-10\% FBS on polymer matrix-coated dishes for $24 \mathrm{~h}$. After this incubation period, the cells were fixed with $4 \% p$-formaldehyde in PBS for $15 \mathrm{~min}$, permeabilized with cold methanol for $4 \mathrm{~min}$, and stained with fluorescein-labelled phalloidin (1:100) for $1 \mathrm{~h}$ at room temperature. Images were recorded and 
analysed using a Nikon-5000 fluorescence microscope and a digital camera.

\subsection{Evaluation of osteoblastic differentiation}

Osteoblastic differentiation was evaluated by measuring two markers, alkaline phosphatase activity (ALP) and the quantitation of type I collagen production, using a Sirius red-based colorimetric microssay (Tullberg-Reinert and Jundt, 1999). ALP was assayed as previously described (Cortizo and Etcheverry, 1995; Molinuevo et al., 2004). Briefly, the cell monolayer was washed with PBS and solubilized in $0.5 \mathrm{ml} \mathrm{0.1 \%}$ Triton X-100. Aliquots of the total cell extract were used for protein determination by the Bradford technique (Bradford, 1976). Measurement of ALP was carried out by spectrophotometric determination of initial rates of hydrolysis of $p$-nitrophenyl-phosphate (p-NPP) to $p$-nitrophenol (p-NP) at $37^{\circ} \mathrm{C}$ for $10 \mathrm{~min}$. The production of $\mathrm{p}-\mathrm{NP}$ was determined by absorbance at $405 \mathrm{~nm}$. Under our experimental conditions, p-NP production was linear for $15 \mathrm{~min}$.

For type I collagen production, cells were fixed in Bouin's fluid for $1 \mathrm{~h}$, washed with water and stained with Sirius red dye for $1 \mathrm{~h}$. The stained material was dissolved in $0.1 \mathrm{~N}$ sodium hydroxide and the absorbance read at $550 \mathrm{~nm}$. Aliquots of the total cell extract were used for protein determination, as described above.

\subsection{Statistical analysis}

Results were expressed as the mean \pm SEM and were obtained from two separate experiments performed in triplicate. Differences between the groups were assessed by one-way ANOVA using the Tukey post hoc test. For non-Normal distributed data, the non-parametrical Kruskal-Wallis test with Dunn post hoc test was performed, using GraphPad In Stat, version 3.00 (Graph Pad Software, San Diego, CA, USA). $p<0.05$ was considered significant for all statistical analyses.

\section{Results}

\subsection{Film characterization}

In this work we studied four different polymers. Two of them were polyesters, poly- $\beta$-propiolactone and poly- $\varepsilon$ caprolactone, which differ in the number of methylene groups, and thus in their polarity and other relevant physical properties (Figure 1). The other two polymers (PDIPF, PDCF) were esters derived from fumaric acid, whose structures are characterized by different alkyl ester groups. Table 1 presents the relevant physicochemical properties (average molecular weight and polydispersity index) of these polymers. We characterized the polymeric surfaces by SEM (Figure 2) and hydrophilicity by water contact angle measurements (Figure 3). The SEM studies revealed that PDIPF film presents a smooth surface, with some crystals of $2 \mu \mathrm{m}$ in size (Figure 1A), while PDCF film shows the smoothest surface without porosity, although with large fissures all over its surface (Figure 1B). On the other hand, PBPL films present a heterogeneous surface with micro pore size $<5 \mu \mathrm{m}$ (Figure 1C). PECL exhibited large fissures and their propagation had the appearance of rugosities on the surface (Figure 1D). These films had pores with sizes in the range $1-5 \mu \mathrm{m}$.

The water contact angle can be used as an indicator for the hydrophilicity of the surface films. According to those measurements, the hydrophilicity increased in the following order: PDCF $<$ PDIPF $<$ PECL $<$ PBPL. This observation indicates, as expected, that polyesters are more hydrophilic that the polyfumarates.

\subsection{Biodegradation}

Our previous results demonstrated that no significant change in the average molecular weight $\left(M_{n}\right)$ of PBPL occurred up to the first 2 days of incubation in PBS buffer (Cortizo et al., 2001). However, after 7 days, $M_{n}$ decreased to $45 \%$ and the polydispersity index increased, as could be expected based on the random nature of the

Structure of the polymers used in this study<smiles>CC(C)(C)C(C(=O)O)C1C(=O)OCC1(C)C</smiles><smiles>[Y]C(CC)(CC1(C)CC1)C(=O)OCC</smiles>

$\mathrm{R}=$

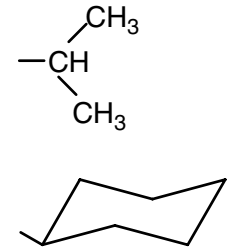

Poly(diisopropyl fumarate)

Poly(dicyclohexyl fumarate)

$$
\begin{aligned}
& x=2 \text { Poly( } \beta \text {-propiolactone) } \\
& =5 \text { Poly ( } \varepsilon \text {-caprolactone })
\end{aligned}
$$

Figure 1. Chemical structure of the polyfumarates and polyesters used for scaffold preparation 


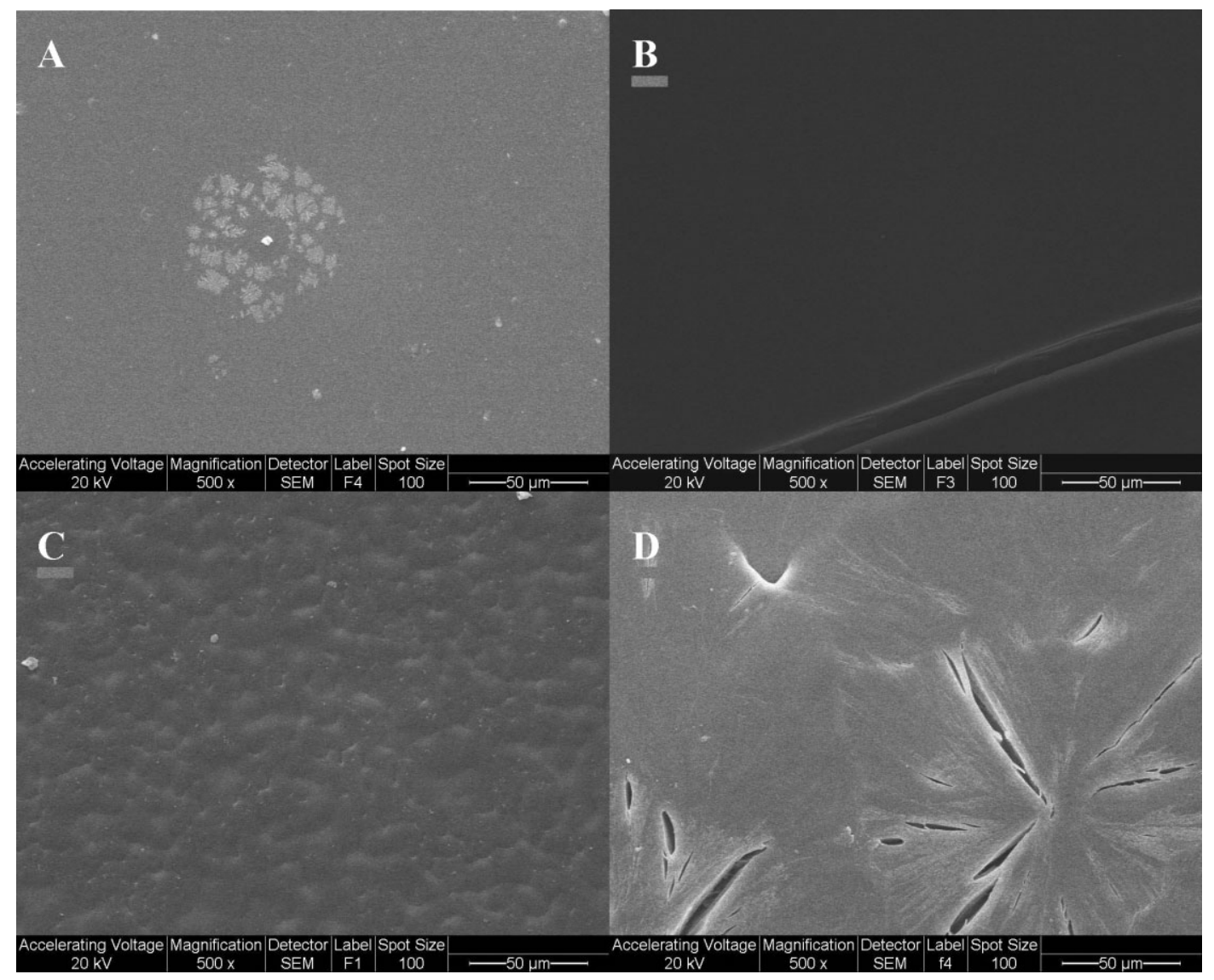

Figure 2. Scanning electron micrographs of the polymeric scaffolds: (A) PDIPF; (B) PDCF; (C) PBPL; (D) PECL. Magnification, $\times 500$
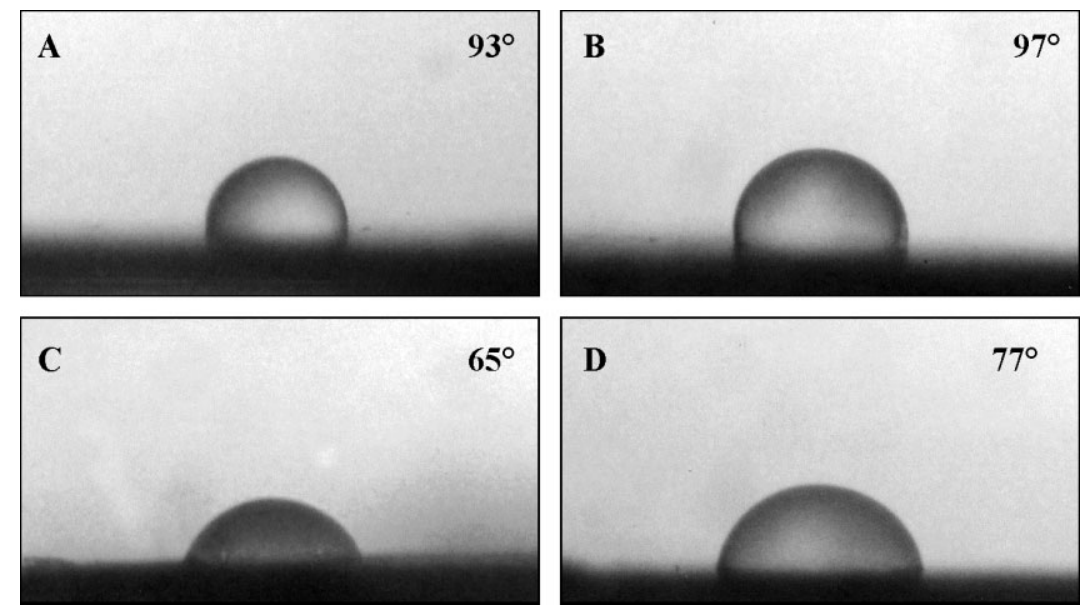

Figure 3. Photographs of water contact angles for films: (A) PDIPF; (B) PDCF; (C) PBPL; (D) PECL

hydrolytic degradative mechanism. It was also noted that neither PECL nor polyfumarates were degraded under similar conditions after 21 days of incubation (data not shown). Thus, other approaches were performed in order to investigate their possible degradation.

The degradation of the polymeric films by macrophages was evaluated by SEC after 21 days of culture and the results are shown in Table 2 . As can be seen, most of the degradation occurred in the polyester films, PBPL being more degraded (74\%) than PEPL (47\%). These observations are evident from the decrease in the $M_{W}$ and the increase in the polydispersity index. On the other hand, the polyfumarates were also degraded by the macrophages, but in less proportion than polyesters. In fact, the $\mathrm{M}_{\mathrm{w}}$ decreased $34 \%$ and $24 \%$ for PDIPF and PDCF, respectively. These observations suggest that the studied polyfumarates, although possessing a $\mathrm{C}-\mathrm{C}$ main chain, can be degraded under in vitro cellular conditions.

In addition, a fluorescent PDIPF was prepared and exposed to the action of macrophages for 21 days. Cells in contact with the PDIPF scaffold showed morphological changes (Figure 4A), from a rounded-monocytic 
Table 2. Film degradation by macrophages ( 21 days): effect on the weight average molecular weight and polydispersity index

\begin{tabular}{lcccc}
\hline Polymer & $M_{w}$ initial & $M_{w} / M_{n}$ initial & $M_{w}$ degraded & $M_{w} / M_{n}$ degraded \\
\hline PBPL & 45100 & 1.4 & 11730 & 5.8 \\
PECL & 24900 & 1.3 & 13200 & 3.5 \\
PDIPF & 74000 & 1.9 & 48840 & 2.8 \\
PDCF & 84700 & 3.6 & 64400 & 4.5 \\
\hline
\end{tabular}

appearence to an activated phagocytic phenotype. The fluorescence microscopy image (Figure 4B) shows the fluorescence associated with the cell cytoplasm, indicating that the polymer can be degraded by a phagocytic process, as has been demonstrated for other polymers of similar structural characteristics (Mabilleau et al., 2004).

\subsection{Cell morphology assessment}

The morphological characteristics of osteoblastic cells growing on different polymeric films were assessed by evaluating actin stress fibres with FITC-pallodin. As can be seen in Figure 5, cells can attach and proliferate on both plastic (control, Figure 5A) and polymeric scaffolds (Figure 5B-E), and develop detectable actin stress fibres. Osteoblastic cells develop cell-cell contacts as well as cell-surface interactions, without evidence of cytotoxicity (cellular shrinkage) under our culture conditions.

\subsection{Adhesion and growth of osteoblastic cells on polymeric scaffolds}

The adhesion process was studied after $1 \mathrm{~h}$ incubation at $37^{\circ} \mathrm{C}$. The adhesion of osteoblasts to different matrices is shown in Figure 6A. As can be seen, the number of UMR106 osteoblasts which adhered to the PBPL-based film was higher that the number attached to the PECL and polyfumarate (PDIPF and PDCF) matrices. On the other hand, the adhesion of MC3T3E1 osteoblasts to polyfumarate was comparable to that on plastic. It was also observed that more cells attached to PECL films

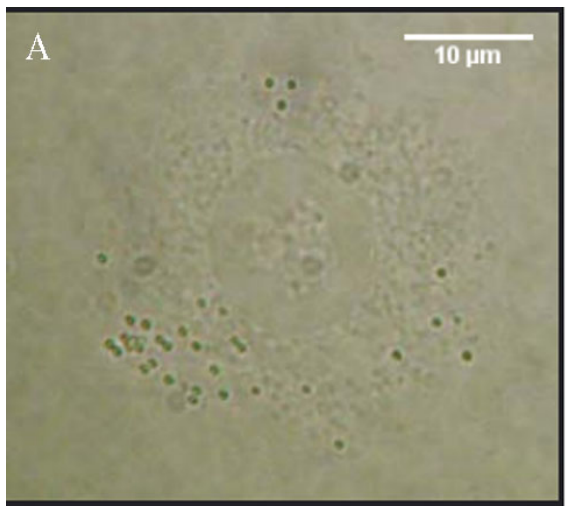

(Figure 6A), while a decrease in adhesion was found with the PBPL film.

The effects of different matrices on the growth of osteoblastic cells were assessed by protein content determination (Figure 6B). Protein content was measured after $48 \mathrm{~h}$ of culture in lysates of cells grown either on plastic tissue culture dishes (control) or the different polymeric matrices. Both UMR106 and MC3T3E1 osteoblastic lines showed protein levels comparable to control conditions, demonstrating that they grow well on all surfaces (Figure 6B). However, the UMR106 cells showed a significant increase in proliferation on the polyester-derived scaffolds (PBPL and PECL; Figure 6B).

\subsection{Differentiation of osteoblasts on polymeric scaffolds}

The ability of osteoblastic cells to express markers of differentiation associated with bone-forming capacity was evaluated by means of ALP activity and type I collagen production. UMR106 and MC3T3E1 osteoblastic lines growing on plastic or polymeric matrices expressed ALP, indicating that osteoblasts could differentiate well (Figure 7A). However, the ALP activity of UMR106 cells grown on polyfumarate films after $48 \mathrm{~h}$ was significantly higher than that on control plastic dishes (Figure 7A). In the case of the pre-osteoblastic MC3T3E1 line, cells were induced to differentiate by culturing them on the different surfaces in the presence of $\beta \mathrm{GP}$ and AA for 15 days. Under these conditions, cells expressed bone markers such as ALP and type I collagen. Figure 7A shows that MC3T3E1 cells expressed similar levels of this differentiation marker in all polymeric matrices. However, a statistically lower expression of ALP was observed in those cells that were cultured on the PDIPF scaffold (Figure 7A). We also assessed type I collagen production by osteoblasts cultured on polymeric films (Figure 7B). We found similar collagen protein content after $48 \mathrm{~h}$ culture of UMR106 cells on all surfaces. However, when the MC3T3E1 line was induced to differentiate for 15 days, important differences were evident. As can be

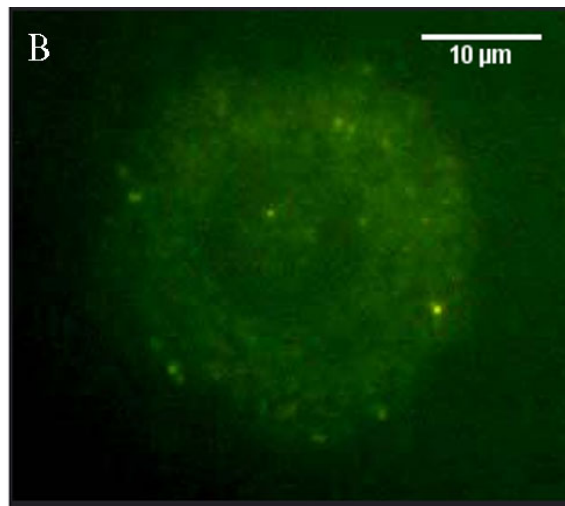

Figure 4. RAW264.7 macrophages growing on PDIPF*. Cells were cultured on a fluorescent PDIPF matrix for 20 days, as described in Materials and methods. Light (A) and fluorescent (B) microscopy revealed the presence of fluorescent particles included in the cytoplasm of activated macrophages 

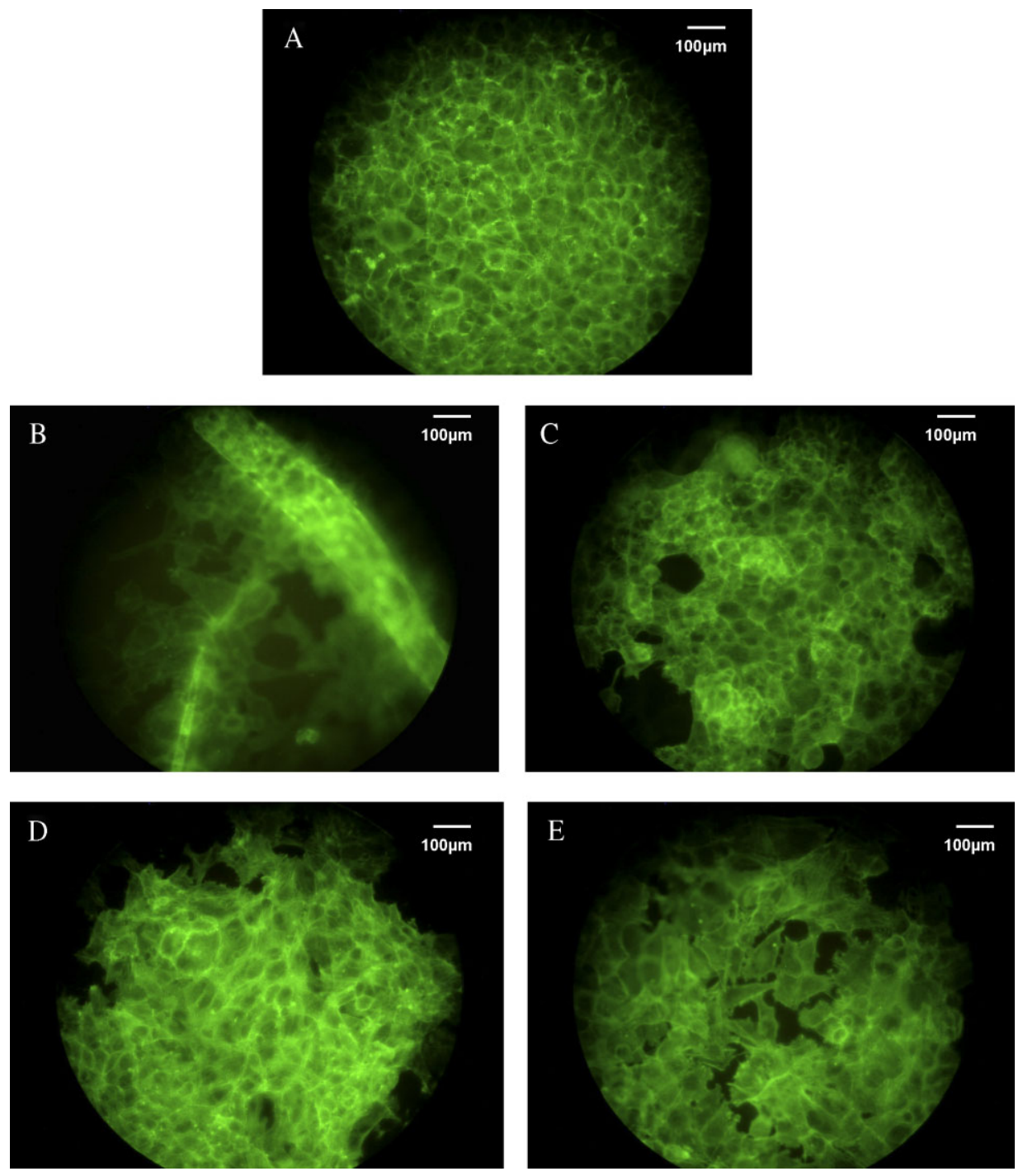

Figure 5. Cytoskeleton organization observed with fluorescent microscopy of actin-stained UMR106 osteoblasts after $24 \mathrm{~h}$ culture on: (A) plastic control dish; (B) PDIPF; (C) PDCF; (D) PBPL; and (E) PECL matrix

seen in Figure 7B, collagen production was significantly lower in the case of osteoblasts grown on both PDCF and PECL-derived matrices than on control (plastic). Interestingly, cells appeared to express higher levels of collagen when they were grown on PBPL-derived scaffolds (Figure 7B), although this was not statistically significant.

\section{Discussion}

Biomaterials play an important role in tissue engineering by serving as scaffolds, which guide tissue regeneration by releasing growth factors that stimulate cell development or by acting as a functional new structure where tissue cells can grow and eventually replace the artificial matrix (Kofron et al., 2004; Lee et al., 2007; Liu et al., 2004). Bioabsorbable polymers are components that can be degraded in vitro as well as in vivo and eventually disappear with time as the tissue is being repaired (Lombello et al., 2002). When temporary presence of a material is needed, such as in the case of wound healing, biodegradation of the matrix without secondary side effects on the surrounding tissues is a desirable property. Moreover, when the scaffolds are used for the regeneration of tissues that must support high mechanical strength, such as in the case of bone tissue, the scaffolds should possess mechanical stability, a controlled degradation rate, no cytotoxicity, and appropriate porosity to allow cell adhesion and growth. In the present study we aimed to develop polymeric-based scaffolds for bone regeneration that would meet these criteria. Two polyesters (PBPL and PECL) and two polyfumarates (PDIPF and PDCF) were chosen to construct films which can support osteoblastic development while being degraded at a convenient rate.

On a synthetic surface, cell adhesion is the consequence of protein adsorption to the substrate and involves many factors, including dipole and electric charge interactions, hydrogen bonds, electrostatic forces, hydrophilicity/hydrophobicity or surface free energy, as well as the roughness and rigidity of the surface (Lombello et al., 2002). The chemical structure of the polymers (Figure 1) 

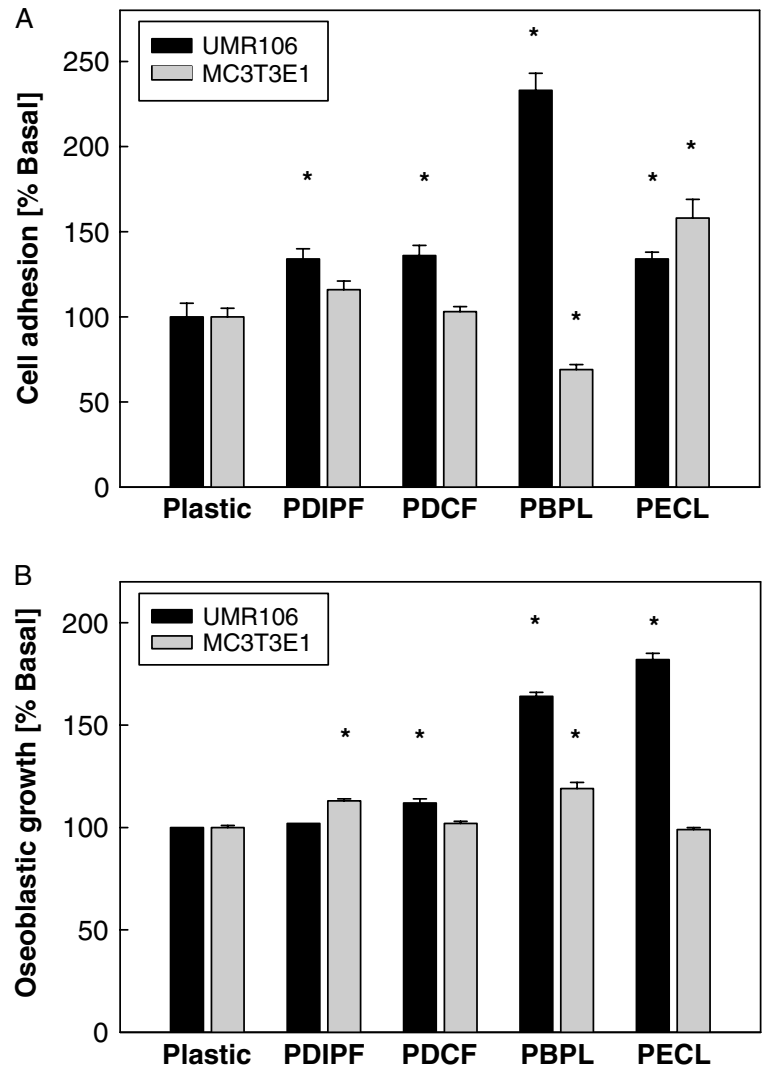

Figure 6. Adhesion (A) and proliferation (B) of osteoblasts on plastic or polymeric scaffolds. Cells were plated on a plastic control dish or on different polymeric matrix-coated dishes and incubated for $1 \mathrm{~h}$ (A) or $48 \mathrm{~h}$ (B). Adhesion and growth were evaluated as described in Materials and methods. Results are expressed as a percentage of basal. Each bar represents mean \pm SEM. ${ }^{*} p<0.05$

indicates that polyfumarates present less polarity and in consequence are more hydrophobic than polyester films. It is known that the physicochemical properties of the different materials mentioned above could bring variations in cell behaviour due to their different surface hydrophobicity, which could influence cell-polymer interactions (Allen et al., 2006). Based on SEM studies and water contact angle, the polyfumarate scaffolds showed smoother and more hydrophobic surfaces. The polyesters films presented more heterogeneous surfaces with micropores and rugosities (Figure 2) and were more hydrophylic. These properties could be determining the relative preference of cells to adhere and grow on polyester films than on polyfumarates matrices (Figure 6).

Biodegradation is an important property in the development of a scaffold for bone regeneration. The chosen polymer must be degraded at a controlled rate in concert with tissue regeneration (Liu and Ma, 2004). Due to their chemical nature, polyesters are capable of being degraded in vitro by non-enzymatic hydrolysis. Other authors have studied the biodegradation of poly- $\varepsilon$-caprolactone in PBS buffer (Yavuz et al., 2002). They found that $M_{n}$ decreased as a function of time (31\% after 30 days) without significant changes in the molecular weight distribution. Our
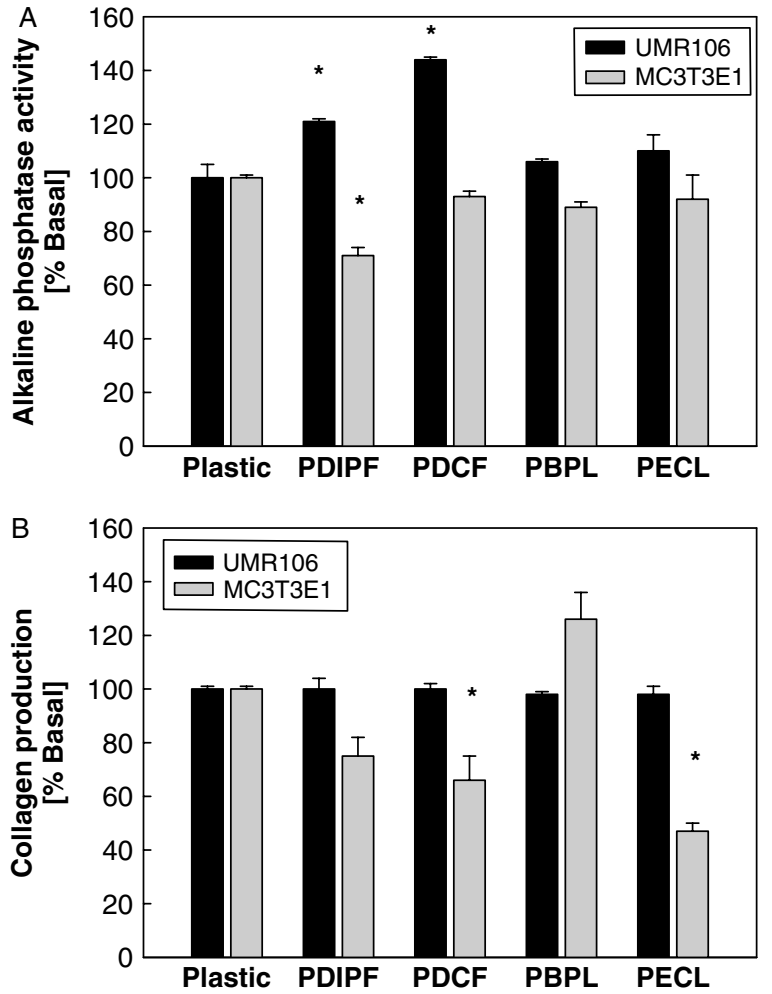

Figure 7. Differentiation of osteoblasts evaluated by alkaline phosphatase activity (A) and type-I collagen production (B). Osteoblasts were grown for $48 \mathrm{~h}$ (UMR106 cells) or 15 days (MC3T3E1 cells) on plastic or different polymeric scaffolds. ALP was evaluated spectrophotometrically by pNP production and collagen formation by staining with Sirius red, as described in Materials and methods. Results are expressed as a percentage of basal. Each bar represents mean \pm SEM. ${ }^{*} p<0.05$

present results obtained under in vitro acellular conditions indicate that the biodegradation of PBPL is faster than that of PECL. These observations are to be expected, due to the higher hydrophobicity of PECL than of PBPL. Conversely, the non-enzymatic hydrolytic mechanism of degradation was observed for polyfumarates. Due to these results, the degradation was re-examined using an in vitro model of fluorescent PDIPF with RAW264.7 macrophages. Cells in contact with PDIPF films showed a morphology compatible with activated macrophages (Figure 4A) and incorporated intracellular fluorescent material (Figure 4B) after 20 days in culture. In addition, macrophages demonstrated a significant degradation of the polymers, indicating that polyfumarates as well as polyesters can be degraded by cellular mechanisms. Mabilleau et al. (2004). studied the degradation of poly(2-hydroxyethyl methacrylate) in vitro with murine macrophage cell line J774.2 and demonstrated that oxidative processes are involved. Thus, similar mechanisms may be operative in our system and additional experiments are in progress in order to further investigate these processes. We found no evidence of cellular toxicity, as determined by an assay of extra-cellular secretion of LDH (data not shown). This intracellular enzyme is liberated to culture media when the cytoplasmic membrane integrity is lost, e.g. in cytotoxic processes. This result suggests that no 
inflammatory process is involved in PDIPF biodegradation. Although more specific in vitro and in vivo studies are needed to accurately confirm this observation, structurally related polymers did not induce inflammatory responses in in vivo studies (Gunatillake and Adhikari, 2003; Jabbari et al., 2005).

The casting method we used in this study provides desirable surface properties necessary for cell attachment and progression. The surfaces adequately support cellular interaction, as we have evaluated by cell adhesion studies (Figure 6A) and cytoskeleton organization (Figure 5). Both physical and topographical characteristics of the polymer have been found to be important in the functional activity of cytoeskeletal proteins and cell morphology (Chesmel and Black, 1995). In the present study, cells developed well-defined actin fibres without evidence of cytotoxicity when growing on the polymers which we have synthesized. Osteoblastic cultures on polymeric scaffolds showed satisfactory adhesion (Figure 6A), except for the MC3T3E1 pre-osteoblasts on PBPL film. However, even in this latter case, after several days of culture the cells proliferated and differentiated very well into a mature osteoblastic phenotype (Figure 7). In concordance with these results, other authors also found that polymers which do not stimulate cell adhesion nevertheless support cellular proliferation (Lombello et al., 2002). Indeed, cells progress to an osteoblastic phenotype, characterized by alkaline phosphatase activity and type I collagen production. The rat osteosarcoma UMR106 line is considered to be in an early mature stage of differentiation. We have found that these cells grow adequately on all our polymeric matrices, albeit with some preference for the polyesters. In contrast, their osteoblastic marker ALP was better expressed when these cells were cultured on polyfumarates. This apparent contradiction is not surprising, since other authors have also demonstrated that materials with a low adhesive potential are essential for maintaining an in vitro differentiated phenotype (Hambleton et al., 1994). On the other hand, the pre-osteoblastic mouse calvariaderived MC3T3E1 cell line grows equally well on all films, although they differentiate better on PBPL after 15 days in culture. These results can be interpreted in the light of the fact the expression of the osteoblastic markers needs the arrest of the genes involved in cellular growth (Quarles et al. 1992). Thus, all in all our results obtained with polymeric matrices indicate that our films are adequate scaffolds for osteoblastic growth.

\section{Conclusions}

The synthetic polymeric-based scaffolds which we have developed and studied are biocompatible and biodegradable by hydrolytic or cellular mechanisms (probably oxidative). The differences in hydrophylicity, indicated by the different substituent groups on the main chain and confirmed by the water contact angle measurements, will allow us to choose the most satisfactory material for each specific application, according to the rate of degradation. The films support adhesion, growth and differentiation of two osteoblastic cells with no evidence of cytotoxicity, indicating that these films could be useful in bone tissue regeneration.

\section{Acknowledgements}

We wish to thank Dr Anthony McCarthy for language improvement of this manuscript. This work was partially supported by grants from Universidad Nacional de La Plata, Comision de Investigaciones Científicas de la Provincia de Buenos Aires (CICPBA) and Agencia Nacional de Ciencia y Tecnologia (BID-1728/OC-AR, PAE 22398) to A.M.C. M.S.C. is a Professor in the UNLP; M.S.M. is a member of the Carrera del Investigador, CONICET; and A.M.C. is a member of the Carrera del Investigador, CICPBA.

\section{References}

Allen LT, Tosetto M, Miller IS, et al. 2006; Surface-induced changes in protein adsorption and implications for cellular phenotypic responses to surface interaction. Biomaterials 27: 3096-3108.

Behravesh E, Zygourakis K, Mikos AG. 2003; Adhesion and migration of marrow-derived osteoblasts on injectable in situ crosslinkable poly(propylene fumarate-co-ethylene glycol)-based hydrogels with a covalently linked RGDS peptide. J Biomed Mater Res A 65: 260-270.

Bradford MM. 1976; A rapid and sensitive method for the quantitation of microgram quantities of protein utilizing the principle of protein-dye binding. Anal Biochem 72: 248-254.

Buma P, Schreurs W, Verdonschot N. 2004; Skeletal tissue engineering-from in vitro studies to large animal models. Biomaterials 25: 1487-1495.

Chesmel KD, Black J. 1995; Cellular responses to chemical and morphologic aspects of biomaterial surfaces. I. A novel in vitro model system. J Biomed Mater Res 29: 1089-1099.

Cortizo AM, Etcheverry SB. 1995; Vanadium derivatives act as growth factor-mimetic compounds upon differentiation and proliferation of osteoblast-like UMR106 cells. Mol Cell Biochem 145: 97-102.

Cortizo MS, Alessandrini JL, Etcheverry SB, et al. 2001; A vanadium/aspirin complex controlled release using a $\operatorname{poly}(\beta$ propiolactone) film. Effects on osteosarcoma cells. $J$ Biomater Sci Polym Edn 12: 945-959.

Cortizo MS, Andreetta HA, Figini RV. 1989; Molecular characterization of poly(diisopropylfumarate) by the absolute calibration method in molecular exclusion chromatography (GPC). J High Res Chromatogr Chromatigr Commun 12: 372-374.

Cortizo MS, Laurella S, Alessandrini JL. 2007; Microwave-assisted radical polymerization of dialkyl fumarates. Rad Phys Chem 76: 1140-1146.

Freyman TM, Yannas IV, Gibson LJ. 2001; Cellular materials as porous scaffolds for tissue engineering. Prog Mater Sci 46: 273-282.

Fini M, Giavaresi G, Setti S, et al. 2004; Current trends in the enhancement of biomaterial osteointegration: biophysical stimulation. Int J Artif Organs 27: 681-690.

Gough JE, Christian P, Unsworth J, et al. 2004; Controlled degradation and macrophage responses of a fluoride-treated polycaprolactone. J Biomed Mater Res A 69: 17-25.

Gunatillake PA, Adhikari R. 2003; Biodegradable synthetic polymers for tissue engineering. Eur Cell Mater 5: 1-16.

Habibovic P, de Groot K. 2007; Osteoinductive biomaterials - properties and relevance in bone repair. $J$ Tissue Eng Regen Med 1: 25-32.

Hambleton J, Schwartz Z, Khare A, et al. 1994; Culture surfaces coated with various implant materials affect chondrocyte growth and metabolism. J Orthop Res 12: 542-552. 
He S, Timmer MD, Yaszemski MJ, et al. 2001; Synthesis of biodegradable poly(propylene fumarate) networks with poly(propylene fumarate)-diacrylate macromers as crosslinking agents and characterization of their degradation products. Polymer 42: $1251-1260$

Hedberg EL, Shih CK, Lemoine JJ, et al. 2005; In vitro degradation of porous poly(propylene fumarate)/poly(DL-lactic-co-glycolic acid) composite scaffolds. Biomaterials 26: 3215-3225.

Hench LL, Polak JM. 2002; Third-generation biomedical materials. Science 295: 1014-1017.

Jabbari E, Wang S, Lu L, et al. 2005; Synthesis, material properties, and biocompatibility of a novel self-cross-linkable poly(caprolactone fumarate) as an injectable tissue engineering scaffold. Biomacromolecules 6: 2503-2511.

Kofron MD, Li X, Laurencin CT. 2004; Protein- and gene-based tissue engineering in bone repair. Curr Opin Biotechnol 15: 399-405.

Lee SJ, Lim GJ, Lee JW, et al. 2006; In vitro evaluation of a poly(lactide-co-glycolide)-collagen composite scaffold for bone regeneration. Biomaterials 27: 3466-3472.

Lee KW, Wang S, Fox BC, et al. 2007; Poly(propylene fumarate) bone tissue engineering scaffold fabrication using stereolithography: effects of resin formulations and laser parameters. Biomacromolecules 8: 1077-1084.

Liu X, Ma PX. 2004; Polymeric scaffolds for bone tissue engineering. Ann Biomed Eng 32: 477-486.

Lombello CB, Santos AR, Malmonge SM, et al. 2002; Adhesion and morphology of fibroblastic cells cultured on different polymeric biomaterials. J Mater Sci Mater Med 13: 867-874.

Lutolf MP, Hubbell JA. 2005; Synthetic biomaterials as instructive extracellular microenvironments for morphogenesis in tissue engineering. Nat Biotechnol 23: 47-55.

Mabilleau G, Moreau MF, Filmon R, et al. 2004; Biodegradability of poly(2-hydroxyethyl methacrylate) in the presence of the J774.2 macrophage cell line. Biomaterials 25: 5155-5162.

Mano JF, Silva GA, Azevedo HS, et al. 2007; Natural origin biodegradable systems in tissue engineering and regenerative medicine: present status and some moving trends. $J R$ Soc Interface 4: 999-1030.

Mano JF, Sousa RA, Boesel LF, et al. 2004; Bioinert, biodegradable and injectable polymeric matrix composites for hard tissue replacement: state of the art and recent development. Com Scs Techno 64: 789-817.

McCarthy AD, Etcheverry SB, Bruzzone L, et al. 1997; Effects of advanced glycation end-products on the proliferation and differentiation of osteoblast-like cells. Mol Cell Biochem 170: 43-51.

McCarthy AD, Uemura T, Etcheverry SB, et al. 2004; Advanced glycation endproducts interfere with integrin-mediated osteoblastic attachment to a type-I collagen matrix. Int J Biochem Cell Biol 36: 840-848.

Molinuevo MS, Barrio DA, Cortizo AM, et al. 2004; Antitumoral properties of two new vanadyl(IV) complexes on osteoblasts in culture. Role of apoptosis and oxidative stress. Cancer Chemother Pharmacol 53: 163-172.

Partridge NC, Alcorn D, Michelangeli VP, et al. 1983; Morphological and biochemical characterization of four clonal osteogenic sarcoma cell lines of rat origin. Cancer Res 43: 4308-4312.

Peter SJ, Miller MJ, Yasko AW, et al. 1998; Polymer concepts in tissue engineering. $J$ Biomed Mater Res 43: 422-427.

Quarles LD, Yahay DA, Lever LW, et al. 1992; Distinct proliferative and differentiated stages of murine MC3T3E1 cells in culture: an in vitro model of osteoblast development. $J$ Bone Miner Res 7: 683-692.

Rosenvasser D, Sagrario Casas A, Figini RV. 1982; Thermodynamic and hydrodynamic properties of aliphatic polyesters, 1 . Solubility, intrinsic viscosity, and molecular weight of poly( $\beta$-propiolactone). Makromol Chem 183: 3067-3073.

Salgado AJ, Coutinho OP, Reis RL. 2004; Bone tissue engineering: state of the art and future trends. Macromol Biosci 4: 743-765.

Sarasam A, Madihally SV. 2005; Characterization of chitosanpolycaprolactone blends for tissue engineering applications. Biomaterials 26: 5500-5508.

Timmer MD, Shin H, Horch RA, et al. 2003; In vitro cytotoxicity of injectable and biodegradable poly(propylene fumarate)-based networks: unreacted macromers, cross-linked networks, and degradation products. Biomacromolecules 4: 1026-1033.

Tullberg-Reinert H, Jundt G. 1999; In situ measurement of collagen synthesis by human bone cells with a Sirius red-based colorimetric microassay: effects of transforming growth factor $\beta 2$ and ascorbic acid 2-phosphate. Histochem Cell Biol 112: 271-276.

Yavuz H, Babaç C, Tuzlakoglu K, et al. 2002; Preparation and degradation of L-lactide and $\varepsilon$-caprolactone homo- and copolymers films. Polym Degrad Stabil 75: 431-437.

Yu ZJ, Liu LJ. 2004; Effect of microwave energy on chain propagation of poly( $\varepsilon$-caprolactone) in benzoic acid-initiated ring opening polymerization of $\varepsilon$-caprolactone. Eur Polym J 40: 2213-2220. 